\title{
Intelligent Modelling Techniques of Power Load Forecasting for the Western Area of Saudi Arabia
}

\author{
A.J. Al-Shareef and M.F. Abbod \\ Elec. \& Comp. Dep., Faculty of Engineering, King Abdulaziz University, \\ Jeddah, Saudi Arabia, and Elec. Dep., School of Engineering and \\ Design, Brunel University, Uxbridge, UK
}

\begin{abstract}
Load forecasting has become in recent years one of the major areas of research in electrical engineering. Most traditional forecasting models and artificial intelligence neural network techniques have been tried out in this task. Artificial neural networks (ANN) have lately received much attention, and a great number of papers have reported successful experiments and practical tests. This paper presents the development of an ANN-based short-term load forecasting model with improved accuracy for the Regional Power Control Centre of Saudi Electricity Company, Western Operation Area (SEC-WOA). The proposed ANN is trained with weather-related data, special events indexes and historical electric load-related data using the data from the calendar years 2003, to 2007 for training. Different neural networks topologies have been trained and tested for achieve the optimal topology and ranking the input variables in terms of their importance. Based on the optimal NN topology, the network has been trained to predict the ahead load at different time intervals.
\end{abstract}

Keywords. Artificial neural networks, short-term load forecasting, back propagation.

\section{Introduction}

Load forecasting has become in recent years one of the major areas of research in electrical engineering. Load forecasting is however a difficult task. First, because the load series is complex and exhibits several levels of seasonality. Second, the load at a given hour is dependent not only on the load at the previous day, but also on the load at the same hour on the 
previous day and previous week, and because there are many important exogenous variables that must be considered ${ }^{[1]}$. Load forecasting plays an important role in power system planning and operation. Basic operating functions such as unit commitment, economic dispatch, fuel scheduling and unit maintenance, can be performed efficiently with an accurate forecast ${ }^{[2-4]}$.

Various statistical forecasting techniques have been applied to Short Term Load Forecasting (STLF). Examples of such methods including, Time series ${ }^{[5,6]}$, Similar-day approach ${ }^{[7]}$, Regression methods $[5,8]$ and expert systems ${ }^{[7,9-10]}$. In general, these methods are basically linear models and the load pattern is usually a nonlinear function of the exogenous variables ${ }^{[1]}$. On the other hand, ANN has been proved as powerful alternative for STLF that it is not relying on human experience. It has been formally demonstrated that ANN's are able to approximate numerically any continuous function to the desired accuracy and it should be expected to model complex nonlinear relationships much better than the traditional linear models that still form the core of the forecaster's methodology. Also, ANN is data-driven method, in the sense that it is not necessary for the researcher to postulate tentative models and then estimate their parameters. Given a sample of input and output vectors, ANN is able to automatically map the relationship ${ }^{[1,11,12]}$.

This paper presents a study on the use of ANN model to STLF, particular attention have been given to the networks topology and the type, different networks were used such as linear, Radial Bases Function (RBF) and Multi-Layer Perceprton (MLP). Furthermore, the input variables to the model were ranked according to their importance using the sensitivity analysis method. The data used for training the system was a typical 24-hours load for the Western area of Saudi Arabia. Time, weather, special season events, and load related inputs are considered in this model. Four years of historical dependent data were used. The forecasting system design was customised to features of Saudi Arabia (SEC-WOA) electrical load.

\section{Load Features of SEC-WOA}

Western operational area of Saudi Electricity Company is covering very important cities with special features. It includes the two holy mosques in Makkah and Al-Madina, beside, the most economical and 
tourism city like Jeddah and other small cites such as Taif and Yanbu. Figure 1 represents the main network of WOA. There are many factors affecting the load of this area, which makes the forecasting unique and challenging.

The weather changes greatly affect the load demand due to a huge air conditioning load in the system. Figure 2 shows a linearity relationship between system daily peak load and related temperature for the year 2004. Another important factor is the time of the day, as social life and activities of the consumers depend on the time of the day such as; working and schools hours and prayer times. In addition to the seasonal load behaviour factor, which reflect how load draws a changeable load profile, because the impact of seasonality. The effect of working days and weekends on the load trend is essential. One more important factor is special events factor mainly religious events such as month of Ramadan and Hajj, and other events such as public holydays, school and exams. These events, based on the lunar calendar will cause un-similarity in load conditions every year, so that it has to be considered.

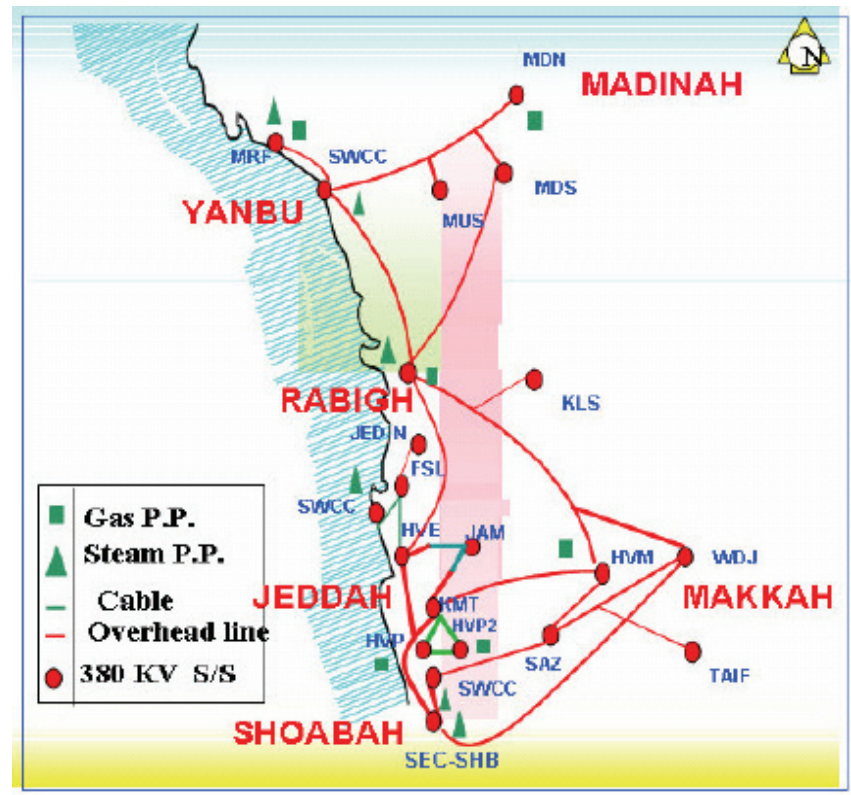

Fig. 1. The main network of WOA.

Examples of a daily load consumption profile of a typical Friday, winter and summer days are shown in Fig. 3. The difference between 
winter and summer profiles is clear; the effect of hot weather is reflected on the great amount of load consumption at afternoon in the summer day. At Friday a sudden increase in the load demand afternoon is due to Friday's prayer, and at weekend the load is stable at morning.

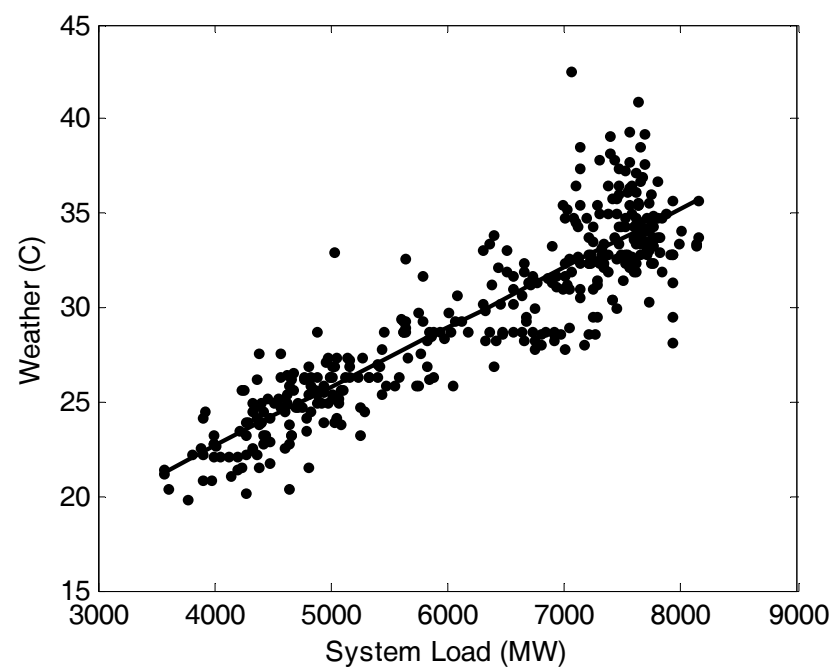

Fig. 2. Relationship between temperature and system daily peak load of 2004.
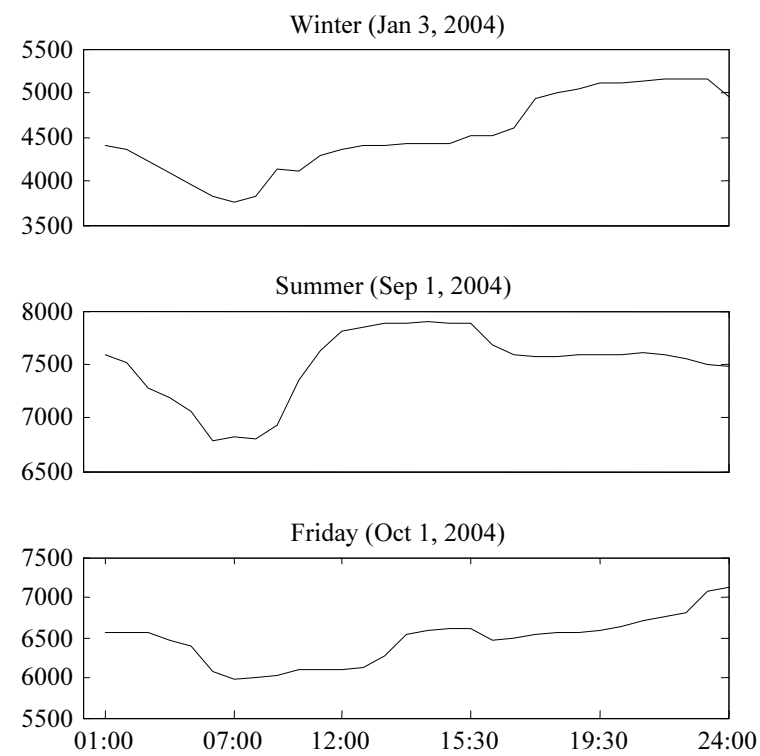

Fig. 3. Examples of daily load consumption profile of a typical Friday, winter and summer days. 


\subsection{Input Vector Configuration}

The independent variables of the system can be specified as the date, time, weather conditions, special events data, and associated historical load data for the day to be forecasted, in hourly bases. Typically, it is configured from month, year, hour, seven indexes represent the day type, six indexes represent the special events, temperature, relative humidity and historical load for the same hour of the last three days, and the same day of the last year. Figure 4 depicts the input vector configuration.

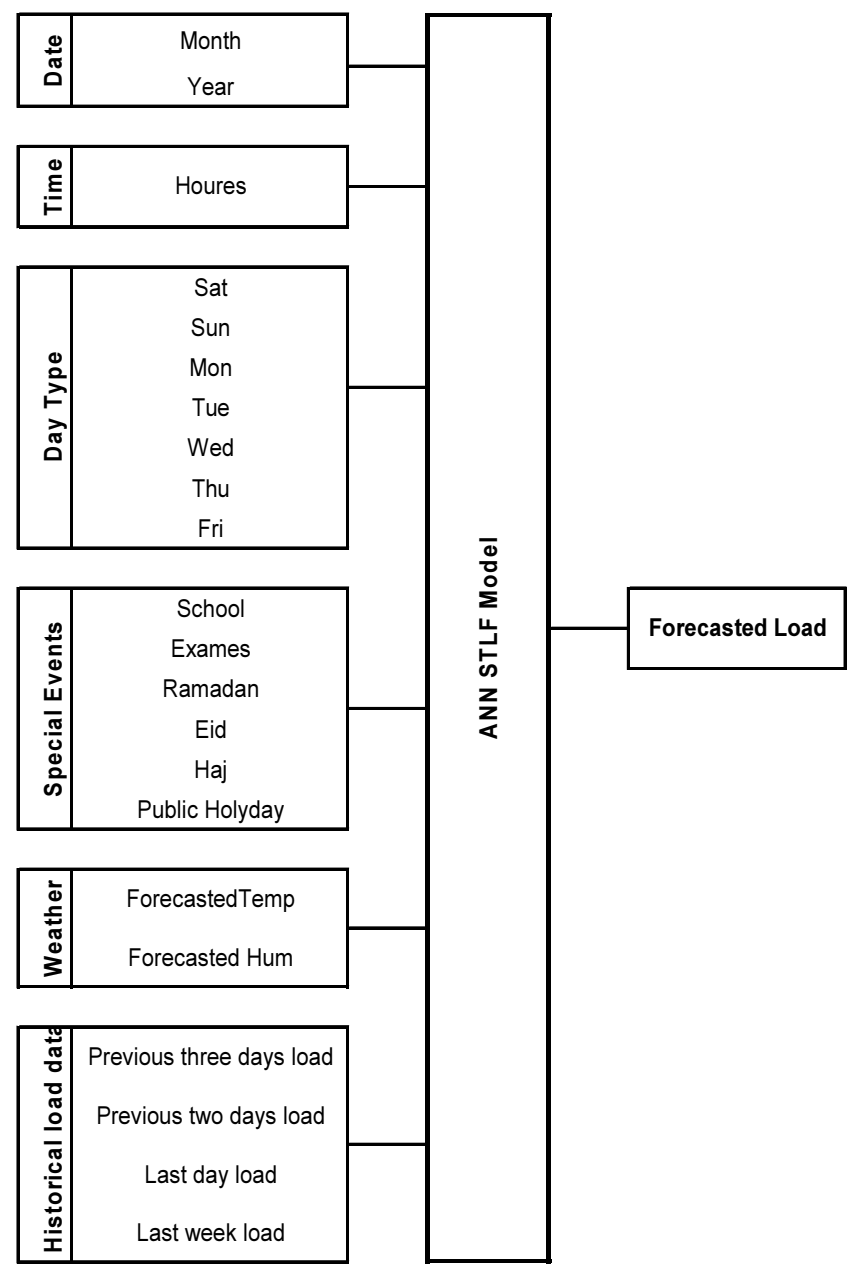

Fig. 4. Input vector configuration. 
Numerical indexes were given to represent the inputs for the forecasted hour. Indexes of $\{1: 12\}$ were given to represent the month, $\{1: 24\}$ to represent the hour and $\{0,1\}$ to represent special events and, the day type starting from Saturday to Friday respectively. Moreover, we have considered half-hourly data for the high load variation periods of the day, typically 13:30,14:30,15:30,18:30,19:30 and 20:30 which were represented by the fractions $(13.5,14.5,15.5,18.5,19.5$ and 20.5) respectively.

\subsection{Data Range}

Since the variety of load shows similarity on the same period each year. Therefore, the limits of two months passing the forecasting day, and two months before and after the same day from each of the previous four years were selected as input data range for the training set (Fig. 5) ${ }^{[3,4,15]}$.

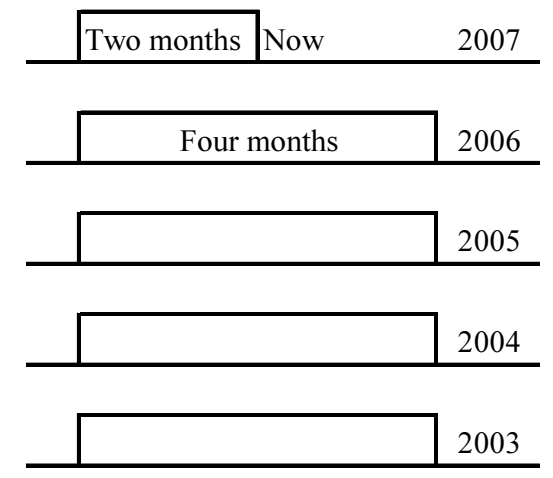

Fig. 5. Limits of Input data range for the training set.

\section{Neural Networks Modelling}

\subsection{Correlation Analysis}

The correlation is one of the most common and useful statistical analysis tools that can be used in data modeling and analysis. A correlation is a number that describes the degree of relationship between two variables. The correlation is defined as the covariance between $\mathrm{Xi}$ and $\mathrm{Xj}$ divided by the product of their standard deviations. Matlab provides a function for calculating the correlation matrix of a set data with multiple variables. A correlation study has been conducted to test the relationship between the input variables and the load. The aim of this 
test is to see how much each variable is related to the load forecasting, so the variable can either be considered as important or redundant that can be dropped from the data set for the purpose of simplifying the developed models. Table 1 shows the correlation matrix. An extra input variable has been added to the data set as the day number in the week (1:Sun - 7:Fri). The correlation matrix shows that the month, year, time and day type variables have considerable correlation to the output, while the temperature and humidity have significant correlation with the load. Otherwise, the other variables, day and day name have low correlation which concludes that such variable can be dropped from the data set.

Interesting enough, there is a negative correlation between the temperature and the humidity as the temperature increases, the humidity will decrease.

Table 1. Correlation table of the load with respect to the individual input variables.

\begin{tabular}{|l|l|c|c|}
\hline \multicolumn{2}{|c|}{ Input variables } & Load & Rank \\
\hline \multirow{4}{*}{ Date } & Day & 0.0949 & $\mathbf{7}$ \\
\cline { 2 - 4 } & Month & $\mathbf{0 . 1 8 4 3}$ & $\mathbf{3}$ \\
\cline { 2 - 4 } & Year & $\mathbf{0 . 1 3 2 3}$ & $\mathbf{5}$ \\
\hline Time & Hours & $\mathbf{0 . 1 8 2 6}$ & $\mathbf{4}$ \\
\hline Event & Day type & $\mathbf{- 0 . 1 0 6 0}$ & $\mathbf{6}$ \\
\hline \multirow{4}{*}{ Weekday } & Saturday & 0.0501 & 9 \\
\cline { 2 - 4 } & Sunday & 0.0367 & 11 \\
\cline { 2 - 4 } & Monday & 0.0378 & 10 \\
\cline { 2 - 4 } & Tuesday & 0.0096 & 14 \\
\cline { 2 - 4 } & Wednesday & -0.0124 & 13 \\
\cline { 2 - 4 } & Thursday & -0.0300 & 12 \\
\cline { 2 - 4 } & Friday & -0.0907 & 8 \\
\hline \multirow{4}{*}{ Atmosphere } & Temperature & $\mathbf{0 . 8 1 0 8}$ & $\mathbf{1}$ \\
\cline { 2 - 4 } & Humidity & $\mathbf{- 0 . 5 0 6 5}$ & $\mathbf{2}$ \\
\hline
\end{tabular}

\subsection{Neural Network Training}

The NN models developments were performed using the Matlab Neural Networks Toolbox.The initial NN models were trained for the data using 5 input variables: Time, Month, Day Type, Year, Temperature, Humidity. While the output is the load. Different NN topologies were trained using back propagation training algorithm and tested in order to find the best network structure that gives the best modelling accuracy. The NN topologies were selected as: Linear, Multi- 
Layer Perceptron (MLP) and Radial Basis Functions (RBF). A maximum two hidden layers were selected ${ }^{[14,16,17]}$. The MLP activation functions were sigmoid for the hidden layer and linear for the output layer. The data were selected as $60 \%$ for training, $20 \%$ for validation, and $20 \%$ for testing. Table 2 shows the training results for different NN topologies where each topology is listed on the first column. Two measures were selected; the performance of the network (standard deviation) and the prediction error (root mean square). Both were evaluated for the training, validation and testing. Based on the training and testing error, the RBF network with 351 hidden neurons is the best selected network which has been developed to predict the load on the network.

\subsection{Sensitivity Analysis}

Sensitivity analysis can give important insights into the usefulness of individual variables. It often identifies variables that can be safely ignored in subsequent analyses, and key variables that must always be retained. However, it must be deployed with some care, for reasons that are explained below.

Table 2. Initial network training.

\begin{tabular}{|l|l|l|l|l|l|l|l|}
\hline \multicolumn{1}{|c|}{ Topology } & $\begin{array}{c}\text { Training } \\
\text { performance }\end{array}$ & $\begin{array}{c}\text { Validation } \\
\text { performance }\end{array}$ & $\begin{array}{c}\text { Testing } \\
\text { performance }\end{array}$ & $\begin{array}{c}\text { Training } \\
\text { error }\end{array}$ & $\begin{array}{c}\text { Validatio } \\
\text { n error }\end{array}$ & $\begin{array}{c}\text { Testing } \\
\text { error }\end{array}$ & $\begin{array}{c}\text { Hidden } \\
\text { neurons }\end{array}$ \\
\hline Linear 5-1 & 0.584462 & 0.580544 & 0.533178 & 0.120806 & 0.123714 & 0.117043 & 0 \\
\hline MLP 5-6-1 & 0.379068 & 0.362919 & 0.362759 & 0.078362 & 0.077329 & 0.079317 & 6 \\
\hline MLP 5-7-1 & 0.362274 & 0.356686 & 0.347462 & 0.074883 & 0.076000 & 0.075990 & 7 \\
\hline RBF 5-233-1 & 0.298338 & 0.316573 & 0.306457 & 0.000215 & 0.000235 & 0.000233 & 233 \\
\hline RBF 5-351-1 & 0.281445 & 0.313537 & 0.294488 & 0.000203 & 0.000233 & 0.000225 & 351 \\
\hline
\end{tabular}

Input variables are not, in general, independent - that is, there are interdependencies between variables. Sensitivity analysis rates variables according to the deterioration in modeling performance that occurs if that variable is no longer available to the model. In so doing, it assigns a single rating value to each variable. However, the interdependence between variables means that no scheme of single ratings per variable can ever reflect the subtlety of the true situation ${ }^{[18]}$.

Consider, for example, the case where two input variables encode the same information. A particular model might depend wholly on one, wholly on the other, or on some arbitrary combination of them. Then sensitivity analysis produces an arbitrary relative sensitivity to them. Moreover, if either is eliminated the model may compensate adequately because the other still provides the key information. It may therefore rate 
the variables as of low sensitivity, even though they might encode key information. Similarly, a variable that encodes relatively unimportant information, but is the only variable to do so, may have higher sensitivity than any number of variables that mutually encode more important information.

There may be interdependent variables that are useful only if included as a set. If the entire set is included in a model, they can be accorded significant sensitivity, but this does not reveal the interdependency. Worse, if only part of the interdependent set is included, their sensitivity will be zero, as they carry no discernable information.

In summary, sensitivity analysis does not rate the "usefulness" of variables in modeling in a reliable or absolute manner. You must be cautious in the conclusions you draw about the importance of variables. Nonetheless, in practice it is extremely useful. If a number of models are studied, it is often possible to identify key variables that are always of high sensitivity, others that are always of low sensitivity and "ambiguous" variables that change ratings and probably carry mutually redundant information ${ }^{[18]}$. The sensitivity metrics shown in Table 3 displays the basic measure of sensitivity (ratios of 1.0 or lower indicate an irrelevant or even damaging input variables, progressively higher values indicate more important variables) while the ranking simply indicates the ordering of the ratios.

Table 3. Input variables sensitivity analysis presented by (error/base line) and ranking.

\begin{tabular}{|l|c|c|c|c|c|c|c|c|c|c|}
\hline \multirow{2}{*}{ Topology } & \multicolumn{2}{|c|}{ Month } & \multicolumn{2}{c|}{ Time } & \multicolumn{2}{c|}{ Day type } & \multicolumn{2}{c|}{ Temperature } & \multicolumn{2}{c|}{ Humidity } \\
\cline { 2 - 12 } & error & rank & error & rank & error & rank & error & rank & error & rank \\
\hline Linear 5-1 & 1.002755 & 5 & 1.007631 & 3 & 1.013084 & 2 & 1.765366 & 1 & 1.003770 & 4 \\
\hline MLP 5-6-1 & 2.425457 & 1 & 1.176136 & 3 & 1.038706 & 5 & 1.788865 & 2 & 1.126097 & 4 \\
\hline MLP 5-7-1 & 2.613937 & 1 & 1.175236 & 3 & 1.066568 & 5 & 1.796174 & 2 & 1.128720 & 4 \\
\hline RBF 5-233-1 & 2.873212 & 1 & 1.666626 & 3 & 1.174538 & 4 & 2.030437 & 2 & 1.082078 & 5 \\
\hline RBF 5-351-1 & 3.168704 & 1 & 1.637669 & 3 & 1.233574 & 4 & 2.320338 & 2 & 1.167711 & 5 \\
\hline
\end{tabular}

Variable ranking is an important issue in selecting which is the best variable that contributes to the output prediction. Although the correlation matrix shows the correlation between each variable and the output, it is based on a linear relationship between the variable. An ANN model is basically a non-linear model which presents the non-linear relationship between the process variables based on trained network. The trained networks shows that for the MLP network with 6 neurons in the 
hidden layer has the month type as the number 1 variable, then temperature, time, humidity and finally the day type. As found earlier, the humidity has high negative correlation with the temperature so it can be considered as a subset of the temperature. This is the reason why it is selected as the least important variable.

Table 4 gives a summary of the descriptive statistics of the different networks shown that the RBF 5-351-1 network has the best correlation (0.958) between the actual and predicted data.

Table 4. Statistical analysis.

\begin{tabular}{|l|c|c|c|c|c|}
\hline & Linear 5-1 & MLP 5-6-1 & MLP 5-7-1 & RBF 5-233-1 & RBF 5-351-1 \\
\hline Data Mean & 5626.213 & 5626.213 & 5626.213 & 5626.213 & 5626.213 \\
\hline Data S.D. & 1421.164 & 1421.164 & 1421.164 & 1421.164 & 1421.164 \\
\hline Error Mean & -9.804 & -8.737 & -9.963 & 3.934 & -17.360 \\
\hline Error S.D. & 810.118 & 520.372 & 503.421 & 443.898 & 406.533 \\
\hline Abs E. Mean & 633.751 & 408.840 & 393.577 & 346.208 & 316.200 \\
\hline S.D. Ratio & 0.570 & 0.366 & 0.354 & 0.312 & 0.286 \\
\hline Correlation & 0.822 & 0.931 & 0.935 & 0.950 & 0.958 \\
\hline
\end{tabular}

\section{Modelling Results}

The modelling results shown in this section are based on the trained models which have 5 input variables. For the 5 generated models, the networks have been tested for varying the temperature as the independent variables, and fixing all the other variables to their nominal values. Figure 6(a) shows the relationship between the load and the day type and time as predicted by the RBF. While Fig. 6(b) shows the load variations as a function of month and temperature. Figure 7 shows the entire predicted data against the actual loads.

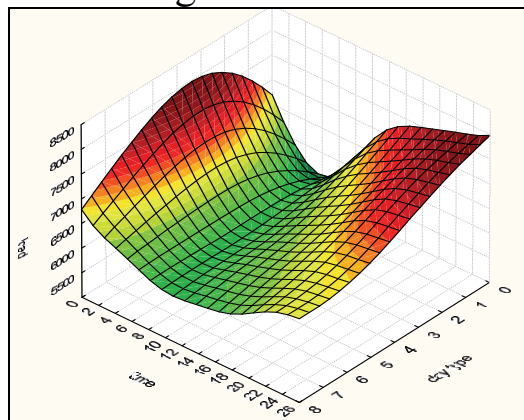

(a)

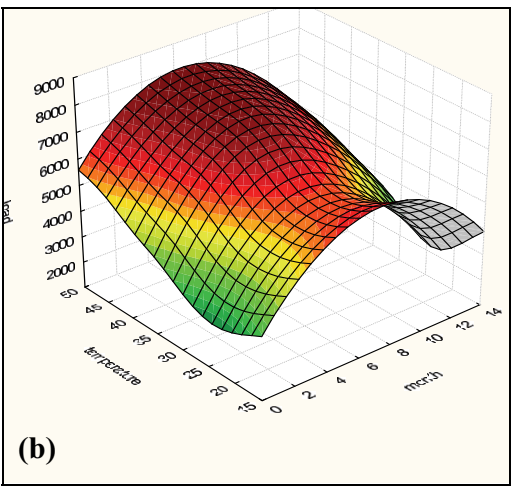

(b)

Fig. 6. Load prediction as a function of: a) Day type and time, b) Month and temperature. 


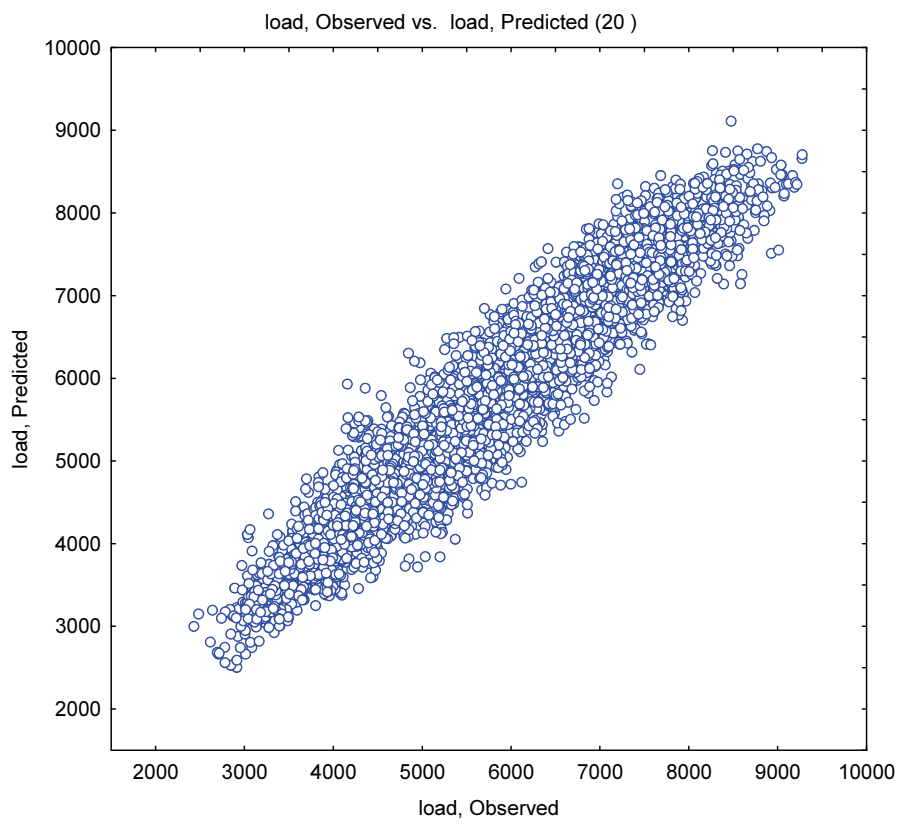

Fig. 7. Plot of the load prediction against actual.

Finally the MLP model was selected for the modelling purpose using different setting, instant, 1 hour, 3 hours, 12 hours and 24 hours prediction. Table 5 shows the different settings of the developed models, including the performance, the error and the networks topologies. Figures 8-12 show the time based prediction for the developed networks.

Table 5. MLP models for different prediction settings.

\begin{tabular}{|l|l|l|l|l|l|l|}
\hline Topology & \multicolumn{1}{|c|}{$\begin{array}{c}\text { Training } \\
\text { performance }\end{array}$} & $\begin{array}{c}\text { Validation } \\
\text { performance }\end{array}$ & $\begin{array}{c}\text { Testing } \\
\text { performance }\end{array}$ & $\begin{array}{c}\text { Training } \\
\text { error }\end{array}$ & $\begin{array}{c}\text { Validation } \\
\text { error }\end{array}$ & $\begin{array}{c}\text { Testing } \\
\text { error }\end{array}$ \\
\hline MLP s1 5:5-121-1 & 0.304134 & 0.336348 & 0.312902 & 0.000217 & 0.000244 & 0.000232 \\
\hline MLP s3 5:15-82-1 & 0.262841 & 0.304820 & 0.290117 & 0.000187 & 0.000219 & 0.000215 \\
\hline MLP s12 5:60-124-1 & 0.248580 & 0.266569 & 0.279048 & 0.000180 & 0.000202 & 0.000213 \\
\hline MLP s24 5:120-351-1 & 0.238343 & 0.260700 & 0 & 0.000169 & 0.000187 & 0 \\
\hline
\end{tabular}




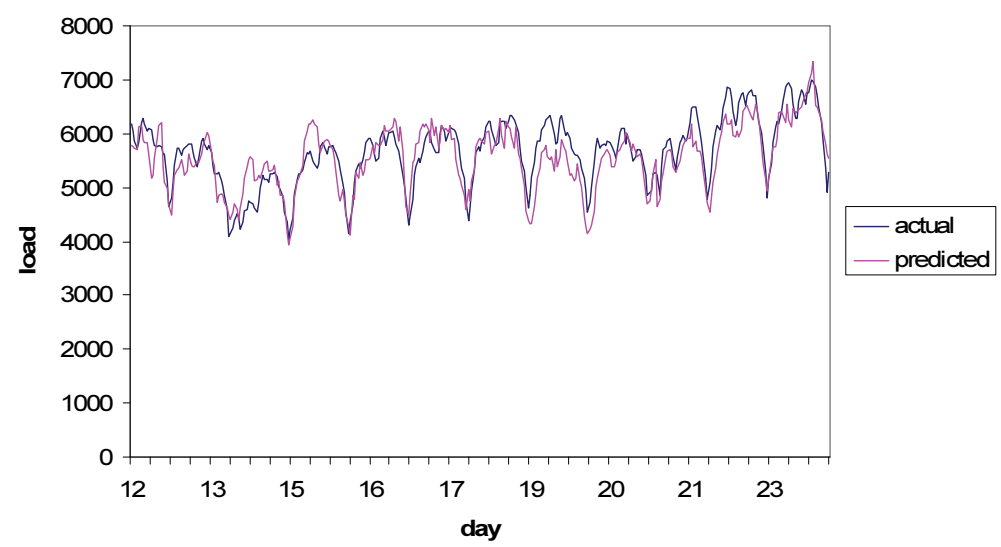

Fig. 8. Instant prediction using MLP 5-6-1.

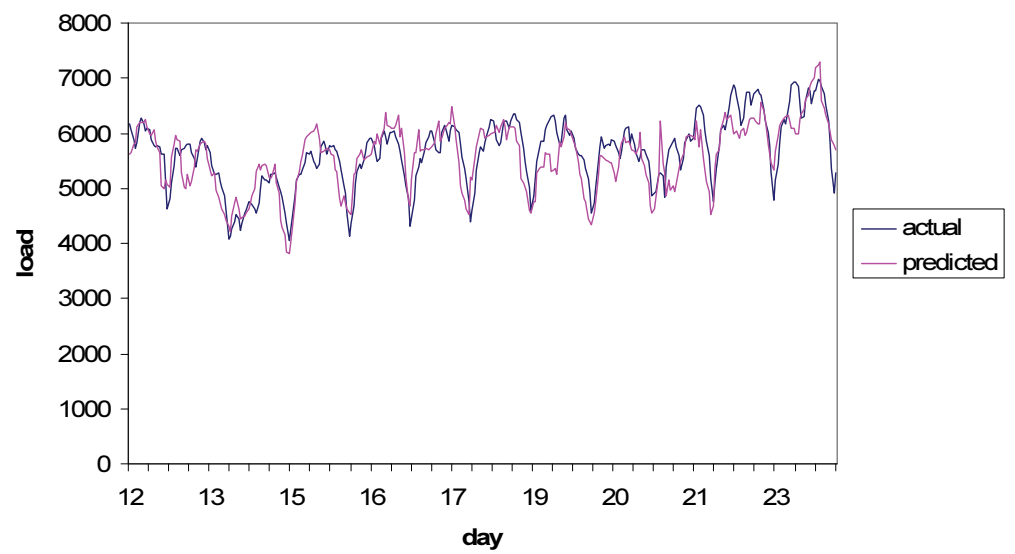

Fig. 9. 1 hour ahead prediction using MLP 5-121-1.

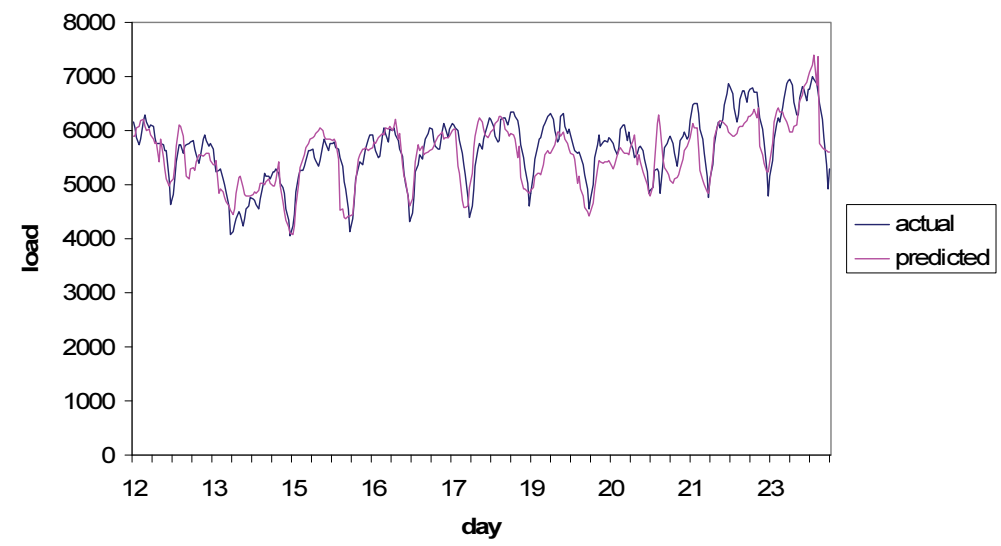

Fig. 10. 3 hour ahead prediction using MLP s3:5-15-82-1. 


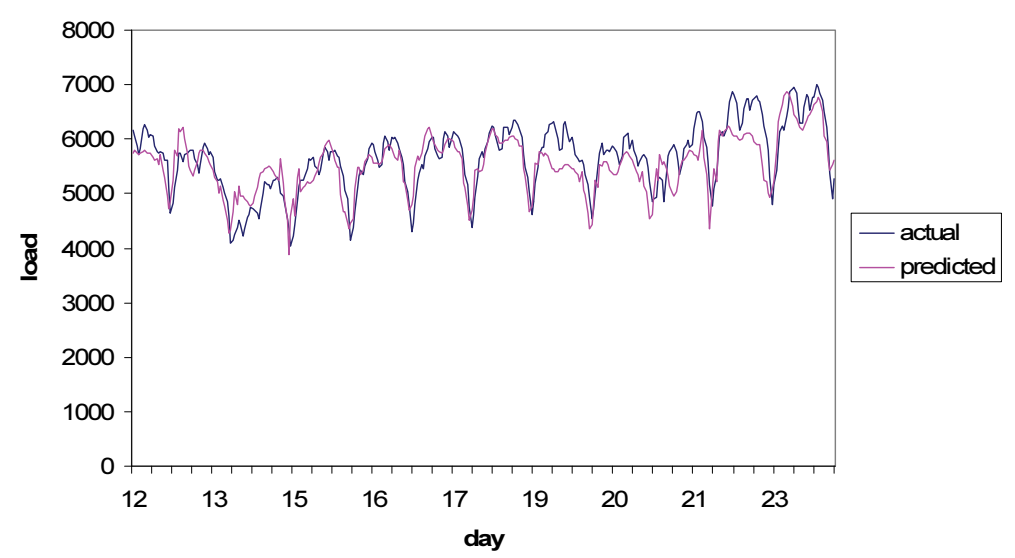

Fig. 11. 12 hour ahead prediction using MLP s12:5-60-124-1.

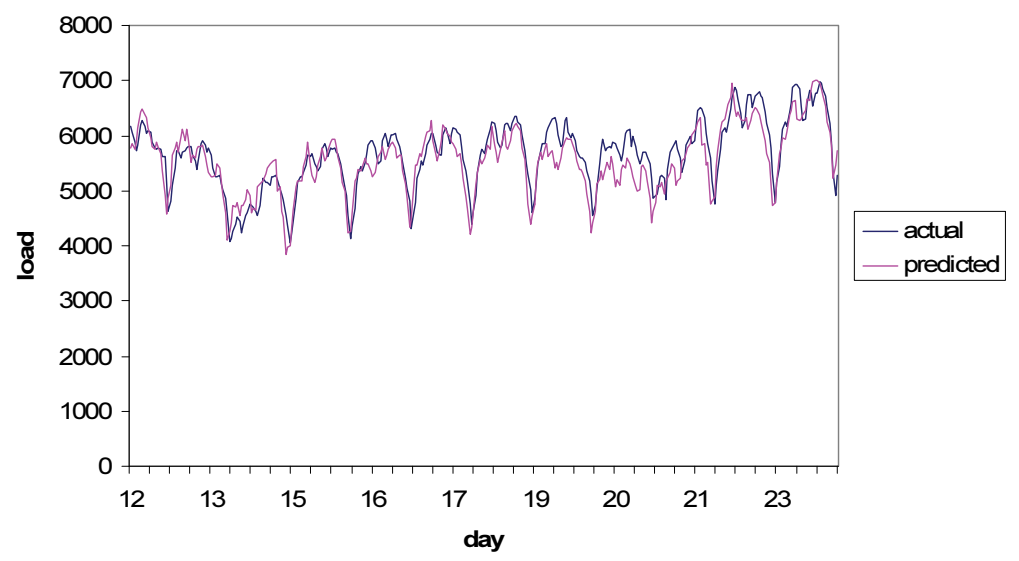

Fig. 12. 24 hours ahead prediction using RBF s24:5-120-351-1.

\section{Conclusions}

This paper presents an ANN based STLF application on the load of SEC-WOA network, in the Kingdom of Saudi Arabia. This network has a load pattern with special features. These features are to cope with the special religious activities of the Kingdom, such as Ramadan and Hajj. Moreover, the load pattern is much affected by the time schedule of the five prayers during the day. Holy cities of Makkah and Madinah host millions of Muslims in different seasons during the year to perform religious activities. In fact, the religious tourism influences the system load profile ${ }^{[19]}$. A seasonal ANN structure is also adopted to handle the 
major contribution of the temperature changes with the four seasons a year, and special events. Different ANN topologies based linear, MLP and RBF types were implemented and evaluated then the inputs variables were ranked according to their importance with different ahead prediction scenarios.

\section{Acknowledgments}

This research is conducted with support from the KSACT, Saudi Arabia. The authors also would like to thank SEC-WOA Company, System Operations and control Department-West, for providing the electrical load and weather data used in this research.

\section{References}

[1] Hippert, H. S., Pedreira, C. E. and Souza, R. C., "Neural networks for short-term load forecasting: A review and evaluation, " IEEE Trans. Power Syst., 16(1): 44-55 (Feb. 2001).

[2] Alsayegh, O. A., "Short-term load forecasting using seasonal artificial neural networks," International Journal of Power and Energy Systems, 23(3):137-142 (2003).

[3] Senjyu, T., Takara, H., Uezato, K. and Funabashi, T., "One hour-ahead load forecasting using neural network," IEEE Trans. Power Systems, 17(1): 113-118 (Feb. 2002).

[4] Baklrtzis, A. G., Petrldis, V., Klartzis, S. J., Alexiadls, M. C. and Malssis, A .H., "A neural network short term load forecasting model for the Greek power system," IEEE Trans. Power Systems, 11(2): 858-863 (May 1996).

[5] Tripathi, M.M. Upadhyay, K.G. and Singh, S.N., "Short-Term Load Forecasting Using Generalized Regression and Probabilistic Neural Networks in the Electricity Market," The Electricity Journal, 21(9): 24-34 (2008).

[6] Taylor, J.W., de Menezes, L.M. and MeSharry, P.E., "A comparison of univariate methods for forecasting electricity demand up to a day ahead, "International Journal of Forecasting, 22: 1-6 (2006).

[7] Drezga, I. and Rahman, S., "Short-term load forecasting with local ANN predictors," IEEE Trans. Power Systems, 14(3): 844-850 (Aug 1999).

[8] Zivanovic, R., Local regression-based-short term load forecasting, Journal of Intelligent \& Robotic Systems, 31(1-3): 115-127 (2001).

[9] Rahman, S. and Hazim, O., "A generalized knowledge-based short term load forecasting technique”, IEEE Trans. Power Systems, 8(2): 508-514 (May 1993).

[10] Kodogiannis, V.S. and Anagnostakis, E.M., "Soft computing based techniques for shortterm load forecasting," Fuzzy Sets and Systems, 128(3) : 413-426 (2002).

[11] Chen, H., Canizares, C.A. and Singh, A., "ANN-based short-term load forecasting in electricity markets," Proceedings of the IEEE Power Engineering Society Transmission and Distribution Conference, 2:411 415 (2001). 
[12] Taylor, J.W. and Buizza, R. "Neural Network Load Forecasting with Weather Ensemble Predictions", IEEE Trans. Power Systems, 17: 626-632 (2002).

[13] Hagan, M. T. Demuth, H. B. and Beale, M.H., "Neural Networks Design," Boston, MA: PWS Publishing (1996).

[14] Haykin, S., "Neural Network: A Comprehensive Foundation," Prentice Hall International, Second edition (1998).

[15] Senjyu, T., Mandal, P., Uezato, K. and Funabashi, T., "Next day load curve forecasting using hybrid correction method", IEEE Trans. Power Systems, 20(1), (Feb 2005).

[16] MacKay, D. J. C., "Bayesian interpolation,” Neural Computation, 4: 415-447 (1992).

[17] Foresee, D. and Hagan, F., "Gauss-Newton approximation to Bayesian learning," International Conference on Neural Networks, 3: 1930-1935 (1997).

[18] Hunter, C.M., Moller, H. and Fletcher, D., "Parameter uncertainty and elasticity analyses of a population model: Setting research priorities for Shearwaters," Ecol. Model., 134: 299324 (2000).

[19] Al-Shareef, A. J., Mohamed, E. A. and Al-Judaibi, E., "One Hour Ahead Load Forecasting Using Artificial Neural Network for the Western Area of Saudi Arabia," International Journal of Electrical Systems Science and Engineering, 1(1): 35-40 (2008). 


\section{النمذجة الذكية و التقنية الأفضل لدر اسة التنبؤ بالأحمال في المنطقة الغربية بالمملكة العربية السعودية}

\section{عبدالعزيز محمد جلال الشريف، و ميسم فاضل عبود قسم العندسة الكهربائية وهندسة الحاسبات، جامعة الملك عبدالعزيز - جدة، وقسم الهندسة الكهربائية، كلية الهندسة و التصديم - جامعة برونيل}

الستخلص. أصبح التنبؤ بالأحمال في السنين الأخيرة واحدًا مــن

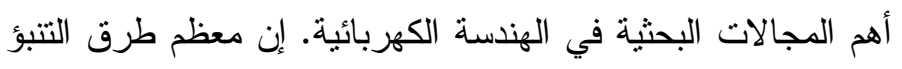

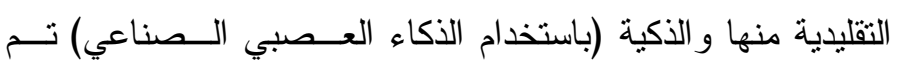
تجربتها وتطبيقها في هذا الجانب. وقد حظيت الثبكات العــصبية

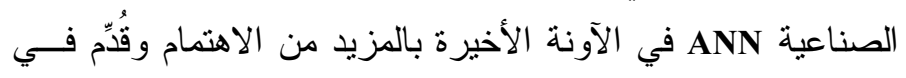
ذلك الكثير من الأبحاث و التجارب الناجحة و الاختبار الاته بات العملية. وتقدم هذه الورقة النطور في نماذج التنبؤ المبني على حمل المدى القصير مع تحسن تقنية التوليد لمركز التحكم الإقليمي للطاقة لشركة الكهرباء السعودية بالمنطقة الغربية. وترتبط الثبكة العصبية الصناعية بظروف المناخ، وكذلك سجل الحو ادث الخاصة بالـشبكة

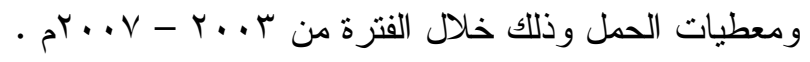
هذا وقد تمت دراسة الخصائص الهندسية للشبكات العصبية،

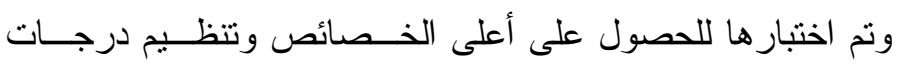

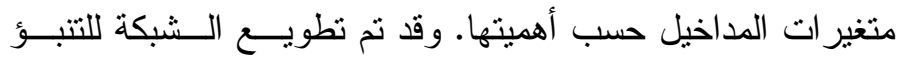
بالأحمال القادمة لفتر ات مختلفة. الكلمات الدالة: الثبكات العصبية الصناعية - حمل المدى القصبر التنبؤ بالحمل - الانتشار المرند. 